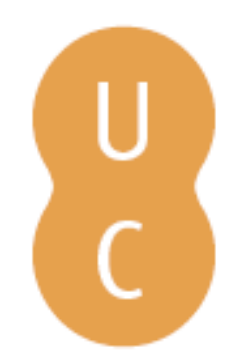

\title{
nombalina
}

Eurípides, Ifigénia entre os tauros: elementos novelescos numa tragédia finissecular

Autor(es): $\quad$ Fialho, Maria do Céu

Publicado por: Imprensa da Universidade de Coimbra

URL

persistente: URI:http://hdl.handle.net/10316.2/38696

DOI: $\quad$ DOI:http://dx.doi.org/10.14195/978-989-26-1164-8_19

Accessed : $\quad$ 26-Apr-2023 13:07:50

A navegação consulta e descarregamento dos títulos inseridos nas Bibliotecas Digitais UC Digitalis, UC Pombalina e UC Impactum, pressupõem a aceitação plena e sem reservas dos Termos e Condições de Uso destas Bibliotecas Digitais, disponíveis em https://digitalis.uc.pt/pt-pt/termos.

Conforme exposto nos referidos Termos e Condições de Uso, o descarregamento de títulos de acesso restrito requer uma licença válida de autorização devendo o utilizador aceder ao(s) documento(s) a partir de um endereço de IP da instituição detentora da supramencionada licença.

Ao utilizador é apenas permitido o descarregamento para uso pessoal, pelo que o emprego do(s) título(s) descarregado(s) para outro fim, designadamente comercial, carece de autorização do respetivo autor ou editor da obra.

Na medida em que todas as obras da UC Digitalis se encontram protegidas pelo Código do Direito de Autor e Direitos Conexos e demais legislação aplicável, toda a cópia, parcial ou total, deste documento, nos casos em que é legalmente admitida, deverá conter ou fazer-se acompanhar por este aviso. 
Maria do Céu Fialho

Universidade de Coimbra / Centro de Estudos Clássicos e Humanísticos

\section{EURÍPIDES, IFIGÉNIA ENTRE OS TAUROS \\ ELEMENTOS NOVELESCOS NUMA \\ TRAGÉDIA FINISSECULAR}

Há mitos e figuras que polarizam, ao longo do percurso de produção de um dramaturgo, o seu imaginário poético: o de Sófocles foi marcado pela figura do cego que vê; o de Eurípides, pelo mito de Tróia e por figuras femininas como Hécuba, Helena, Ifigénia. É percetível que Eurípides, ainda que tivesse trabalhado sob o pressuposto da versão mitológica do mito de Agamémnon e do sacrifício de Ifigénia a que Ésquilo ou Sófocles recorreram, se sentiu profundamente atraído pela versão que viria a explorar, dramaturgicamente, no fim da sua vida, em Ifigénia em Áulide: uma versão provavelmente local e que parece estar já documentada nos Cantos Cíprios ${ }^{1}$. A donzela prestes a ser sacrificada por seu pai, por exigência divina, mas que, por clemência dos próprios deuses, é subtraída ao sacrifício e adequadamente substituída por um animal, parece fazer parte do imaginário mítico do Mediterrâneo Oriental. Recorde-se, por exemplo, o sacrifício de Isaac, exigido a Abraão por Javeh que, no último instante, substitui também o jovem por um animal, no momento em que está já provada a fidelidade do patriarca hebraico.

No entanto, o caso de Ifigénia é algo diverso, pelo menos na dramaturgia euripidiana. Explorado este motivo como sacrifício voluntário - tema tão do gosto do tragediógrafo -, ele tem o seguinte efeito: no momento em que a ação, conduzida pelos senhores da guerra, chegou a uma situação aporética, depois

\footnotetext{
1 Esta peça viria a ser representada na Grandes Dionísias em 406 ou 405 a. C., juntamente com Alcméon em Corinto (composto provavelmente no final da década anterior, próximo de Helena e de Ín) e Bacantes, por iniciativa de um filho de Eurípides, pouco tempo após a morte do dramaturgo, de acordo com a informação de um escólio a Aristófanes, Rãs, 67.
} 
de todo o jogo de intrigas e interesses que se desenvolve à volta do poder, a solução, ou o ultrapassar do impasse fica dependente da decisão de um ser frágil, alheio à vida política, de uma donzela, que está, todavia, no centro da discussão - uma donzela que caminha voluntariamente para a morte, por compreender o peso político que essa sua atitude poderá ter ${ }^{2}$. No entanto, do sacrifício voluntário da donzela desprende-se uma atmosfera dramática de mal-estar que não nobilita os poderosos. Eurípides utiliza a criação dessa atmosfera para aí introduzir a interrogação crítica sobre a legitimidade do conflito bélico e da utilização demagógica do poder ${ }^{3}$.

Em relação à tradição épica da salvação de Ifigénia por Ártemis, que a teria arrebatado para a converter em deusa, Eurípides concebeu uma proposta dramatúrgica inovadora, em Ifigénia entre os Tauros. Não é uma donzela convertida por Ártemis em deusa, mas uma donzela convertida em sacerdotisa da deusa Ártemis que Eurípides nos apresenta. Foi salva e arrebatada para terras bárbaras da actual península de Azov, onde o soberano bárbaro e rude daquelas terras a protege e mantém ao serviço de um culto bárbaro de Ártemis, em conexão com a estatueta de madeira da deusa que, misteriosamente, ali foi parar.

Esta tragédia de fin de siècle, tal como Helena ${ }^{4}$, tal como o Filoctetes de Sófocles, remete o espetador para um espaço de ação fora do comum universo grego: trata-se de um espaço longínquo, de alteridade ou de solidão (no caso de Filoctetes); um espaço que era já conhecido pelo Grego daquele tempo, mas que até então não constituira espaço de uma ação dramática em que as personagens principais são Gregos, fora da sua pátria. O destino destas está tomado por uma dinâmica de circularidade, já que, após o afastamento, após a ação excêntrica,

2 Veja-se A. Henrichs, "Human Sacrifice in Greek Religion: Three Case Studies" in: Le sacrifice dans l'Antiquité, Entretiens de la Fondation Hardt 27 (Genève 1981) 195-235. A mesma dimensão do sacrifício humano, no mito de Ifigénia em Eurípides, é objeto da exegese de H. Lloyd-Jones em "”Artemis and Iphigeneia" JHS 103 (1983) 87-102.

3 Veja-se M. F. Silva, "Sacrifício voluntário. Teatralidade de um motivo euripidiano", Biblos 67 (1991) 15-41.

4 Helena data de 412 a. C. Ifigénia entre os Tauros é-lhe muito próxima, ainda que a sua data não seja conhecida. A proximidade torna-se evidente pela similaridade de motivos, aliás reconhecíveis na novela posterior (uma figura real feminina que, entre Bárbaros, longe da sua terra natal, se encontra com um familiar há muito afastado - irmão, marido - e planeia uma fuga dolosa; os motivo do engano, do mal-entendido, do reconhecimento estão presentes em ambas). Existem, além do mais, similaridades métricas entre ambas, que correspondem a uma última fase da produção euripidiana (M. J. Cropp, Euripides. Iphigenia in Tauris, ed. introd. transl. comment, Warminster, 2000, 60 sqq.; M. Hose, Studien zum Chor bei Euripides II, Stuttgart, 1991, 26 sqq.). 
jogada fora do mundo grego, essa ação conduzi-las-á à pátria e integrará, no próprio universo grego, alargado, elementos desse outro espaço 5 . Com essa integração se esbate, de algum modo, um binómio já há muito ferido: o do Grego/ Bárbaro - ainda que a ingenuidade e amathia do rei Toas o torne inferior ao Grego, arguto, Toas é, contudo, aquele que se mantém fiel aos juramentos e que o Grego ludibria, ganhando proveito da dita amathia ${ }^{6}$.

Diferentemente dos percursos de Ulisses, que são de pura errância e privação do espaço onde pretende chegar - um espaço limitado, que representa o 'esquecimento' dessa errância - estes caminhos da tragédia dos últimos anos do séc. v apontam noutro sentido. Se nos centrarmos especificamente em Ifigénia entre os Tauros, apercebemo-nos de que há elementos que, de algum modo, antecipam a narrativa épica dos Poemas Argonáuticos de Apolónio de Rodes: os viajantes marítimos que chegam a terra bárbara com a missão de daí trazerem para a Hélade um objecto excecional (o xoanon de Ártemis, num caso, o Velo de Ouro, no outro), a centralidade e capacidade de decisão e elaboração de um plano doloso por parte da personagem feminina - no caso de Eurípides, Ifigénia -, a dependência, em relação aos seus planos, dos estrangeiros que chegam, a figura do rei bárbaro, Toas, que, na sua rudeza e rusticidade, se deixa enganar pelo plano posto em prática por Ifigénia e pelos dois estrangeiros, tal como o pai de Medeia. A comunidade dos Tauros tem aspectos comuns à dos habitantes da Cólquida - trata-se de sociedades rurais, em ambos os casos, profundamente

5 A. Delcourt, "Oreste et le prince" EC 66 (1998) 63-64: "L'expédition d'Oreste en terre barbare presente donc aux Grecs du V.e siècle l'image inversée de la polis dans laquelle ils évoluent, et leur donne, par ce jeu de miroirs, conscience de leur identité. Mais elle leur permet aussi d'attribuer à dês rites ressentis comme violents, et qui leur sont familiers, une origine acceptable: c'est à Oreste regagnant la Grèce avec la précieuse effigie taurique que ceux-ci doivent leur introduction. Les cultes d'Artémis Tauropole, Brauronia, Orthia/ Iphigeneia, Skythia sont ainsi placés en étroite relation avec la déesse barbare et mettent à leur profit le succès de la tragédie d'Euripide".

6 Compare-se o papel de Teoclímeno em Helena. Vide E. Hall, Inventing the Barbarian. Greek Self-Definition through Tragedy ( Oxford 1991) 121-122. Sobre a problematização do binómio, veja-se a dissertação de doutoramento de J. R. Ferreira, Hélade e Helenos. Génese e evolução de um conceito (Coimbra 1992) 361-416.

D. J. Conacher, Euripidean Drama. Myth, Theme and Structure (Toronto 1967) 305 vai ao ponto de considerar a peça como transgressora do 'trágico': "The I.T. is another of Euripides' romantic tragicomedies, based like the Helena on the ironic interplay of illusion and reality". À afirmação subjaz uma posição metodológica algo problemática e que consiste em projetar caraterísticas de géneros literários posteriores sobre as tragédias de Eurípides, desvalorizando hermeneuticamente a tragédia de fim de século e descurando a voz de um tempo de crise que nela se faz ouvir. Veja-se M. Quijada Sagredo, "El Eurípides tardío y los límites de la tragedia” in: M. Quijada Sagredo (ed.), Estudios sobre Tragedia Griega. Euripides, el teatro griego de finales del siglo V a. C. y su influencia posterior (Madrid 2011) 40 sqq. 
ligadas à pastorícia e criação de gado, o que contribui para a rudeza ingénua do seu caráter coletivo. A ação, por seu turno, tem, como já foi referido, muitos aspetos em comum com a de Helena.

Eurípides optou por dar ao prólogo da sua peça uma estrutura bipartida. Sem deuses que nele venham expor o curso dos acontecimentos a esperar - o que deixa espaço aberto a esse sentimento de que a Tyche é senhora dos destinos humanos, nele atuam Ifigénia, por um lado, Orestes e Pílades, por outro, sem que aquela e estes se encontrem. Esta estrutura serve para sublinhar até que ponto estão separados os universos de seres física e afetivamente tão próximos - e tal técnica dramatúrgica, pela riqueza de efeitos que traz consigo, será usada por Sófocles, na sua Electra, que não estaria muito distante, no tempo, da tragédia em apreço.

O monólogo inicial de Ifigénia tem, naturalmente, o caráter expositivo que situa o espectador na versão do mito escolhida pelo dramaturgo e no ponto de acção, dentro dessa versão - um ponto de ação que parece ter sido inventado por Eurípides: após os acontecimentos em Áulide, quando Agamémnon, na sequência do oráculo de Calcas, prepara o sacrifício de Ifigénia, atraída ao acampamento militar pelo engano forjado por Ulisses (assim arranca este a donzela à sua casa e à sua mãe) - as falsas núpcias com Aquiles -, Ártemis arrebata a jovem pelos ares para a colocar a salvo, como mortal, no país dos Tauros. Aí deve servir como sacerdotisa da deusa e sacrificar à sua pequena estátua de madeira, num bárbaro culto, todos os Gregos que aí aportem (1-41). A segunda parte deste monólogo (42-66) traz Ifigénia ao seu isolamento e angústia, longe do lar e dos afetos, ignorando o destino de Agamémnon e da sua casa: a morte do rei, seu pai, às mãos de Clitemnestra e a de Clitemnestra às mãos de Orestes, a quem as Erínias perseguem. Por isso mesmo, Ifigénia expõe o seu sonho, como o fazem tantas figuras da tragédia grega, apreensiva com o seu significado. Mas, diferentemente dessas outras figuras que, percebendo claramente ou com menos clareza, o significado ominoso dos seus sonhos, Ifigénia, por desconhecer a realidade lá longe, em Argos, e a presença de Orestes e Pílades bem perto dela, mal-interpreta o seu sonho.

Eurípides constrói magistralmente o sonho, como uma típica sequência, na linguagem onírica, de símbolos que se fundem, se metamorfoseiam e provocam o envolvimento emocional daquele que sonha e se vê a si mesmo, agindo nessa 
floresta de símbolos sem compreender o sentido dos seus gestos. No sonho de Ifigénia, como nota Conacher, se projectam, com verosimilhança, "The feelings and fears of the dreamer: her longing to be home, her anxiety about her family of whom she had no news since Aulis, her love for the infant Orestes (as she knew

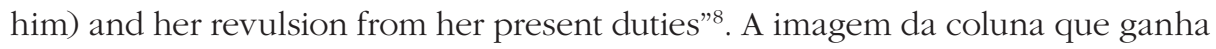
voz, com cabelos semelhantes aos de Orestes, sobre a qual Ifigénia se prepara para fazer os sacrifícios a Ártemis suscita-lhe o sobressalto de que Orestes está privado de vida, já que o pilar da casa é a sua descendência9 . A identificação está certa. A jovem, no entanto, ignorou a simbologia da casa destruída por não conhecer a sorte dos seus familiares. O sacrifício iminente, por seu turno, anuncia a proximidade de Orestes - mas Ifigénia não tem motivos para o supor.

O sonho enganador desperta a nostalgia da pátria. Ifigénia está mais só, presa ao seu múnus de sacerdotisa de um estranho culto a Ártemis, em cujo templo entra. Chegam à cena vazia os dois viajantes gregos, Orestes e Pílades. Pílades não é já a personagem muda esquiliana e Orestes, por seu turno, vem ainda perseguido por algumas das Erínias que se não resignaram com o veredicto do Areópago. Nova tarefa é pedida por Apolo a Orestes, na perspectiva de o livrar da perseguição das deusas - a apropriação e condução para a Hélade da estatueta de Ártemis, associada ao bárbaro culto. As palavras de Orestes são amargas em relação a Apolo: novo oráculo, nova armadilha, após o matricídio (77 sqq.)? Os mortais estão cansados dos estranhos e penosos caminhos que os deuses os fazem percorrer. Por diversas vezes o verbalizam nesta peça. A solução do Areópago e do acolhimento em Atenas não foi suficiente nem eficiente. "Algumas Erínias" não resignadas significa que o hino à democracia, nos tempos da sua consolidação, se calou há muito, pois a própria democracia, lá longe, converteu-se em algo muito diferente do que sonhou ser. A cadeia de vinganças familiares, por sua vez, pesa como excessiva e cruel, como também Electra o denuncia.

\footnotetext{
8 G. M. A. Grube, The Drama of Euripides, London 1941 (new repr. w. corr. New York 1973) 316.

9 J. P. Schwindt, "Tragischer und epischer Traum. Euripides, Iph. Taur. 42-64 und Homer, Od.19. 535-69" Hermes 126 (1998) 1-14, compara o sonho de Ifigénia ao de Penélope, no canto 19 da Odisseia. Esta comparação leva-o à conclusão de que se trata de sonhos tipificados para a caraterização de figuras aristocráticas.
} 
Não estamos já, como o nota Cropp $^{10}$, perante o desenrolar de uma maldição familiar, mas perante um enredamento de acontecimentos e da sorte em que o ser humano se vê enleado, em tempos e espaços diferentes. Eu acrescentaria que esse enredamento projeta os seres humanos para uma proximidade nunca imaginada, quando pensam estar perdidos para sempre uns dos outros. A experiência humana, no mundo, não é a do homem num kosmos, mas num contexto de taragmos ('perturbação'), como dirá Orestes (572-573).

A desilusão democrática e a crise de um sistema em ruínas pesam neste contexto de universo dramático alargado, rasgado por guerras, perseguições, aventuras e fugas, por salvamentos maravilhosos operados pelos deuses, após terem semeado a desordem humana e a dor. Os desencontros entre oráculos e sonhos mal interpretados levam, certamente, o espetador a perceber quão confusa é a comunicação deuses-homens e a perceção das forças que gerem a vida.

À imagem do oráculo de Apolo ao Orestes da Electra sofocliana, também o oráculo de Apolo a Orestes, na presente peça, alude a uma tarefa cujo sucesso não será alcançado através de uma ação nobre e pública, mas de estratagemas (technaisi, 89) ou, neste caso, de um golpe de sorte propícia (tychei, 89). É, pois, frágil a assistência divina. As personagens humanas mais parecem ser deixadas ao sabor da sorte - Tyche, a grande força que determinará o curso de ação e os destinos das personagens da novela helenística - cujo império é ilustrado e sublinhado nesta peça ${ }^{11}$. Ela é a poderosa entidade, atuante na vida humana, que, na Cultura Helenística, é elevada à categoria de divindade. É com o pressuposto da sua força que o imaginário helenístico se abrirá para o tipo de ficção, no teatro ou no novo género, na novela, em que familiares ou um par de enamorados se perde, se julga para sempre perdido, pela morte do outro, e se vem a reencontrar, necessitando, muitas vezes, no caso de irmãos separados na infância, de sinais de reconhecimento que se tornam notórios, por acaso.

$\mathrm{E}$ a tyche tem as suas ironias. O esconderijo procurado por Orestes e Pílades, nas grutas da praia, para aí arquitetarem o plano que à terra dos Tauros os trouxe, leva-os a um espaço frequentado pelos boieiros que assim os descobrirão

10 M. J. Cropp, ibid. (Warminster 2000) 34-35.

11 D. J. Conacher, op. cit. 309. 
e os trarão aprisionados para o sacrifício que Ifigénia deverá realizar. Os próprios deuses parecem ter traído Orestes, já que, quando procurou ocultar-se discretamente nessas grutas, o ataque das Erínias o fez comportar-se como louco. A descrição que Eurípides põe na boca do Mensageiro-Boieiro da sintomatologia de Orestes está muito próxima da de uma crise de epilepsia, "doença sagrada" já familiar aos Gregos na sua manifestação ${ }^{12}$ : depois do comportamento frenético sucede-se a prostração, não descrita em pormenor. Eurípides refere a baba espumosa que sai da boca de Orestes, caído por terra, e a necessidade que Pílades reconheceu de lhe prestar assistência e o cobrir, uma vez deitado no solo (307-314). E assim ambos os Gregos são trazidos para o sacrifício, até uma sacerdotisa para quem, após as impressões do sonho noturno, o seu múnus se torna ainda mais pesado. São apenas mais dois Gregos a sacrificar, perante a sacerdotisa e, todavia, sem o saberem, são os irmãos que estão frente a frente, num universo vasto, percorrido por itinerários e destinos diversos, para se encontrarem num ponto em que um está prestes a matar o outro e o seu amigo, agora também familiar.

Orestes havia já manifestado o seu cansaço existencial, jogado entre Apolo e as Erínias já muito para além do espaço da sua pátria. Já entre os próprios boieiros bárbaros a voz racionalista de um deles levanta-se para desmontar a ingénua suposição de quem pensa que os estrangeiros avistados junto ao mar são divindades - são apenas, como afirma, náufragos que se escondem por receio $(275-278)^{13}$. Confrontada com mais duas vítimas gregas a sacrificar a Ártemis, Ifigénia põe em causa os sophismata da deusa (380), bem como a possibilidade de os deuses gerarem outros deuses de comportamento tão absurdo (tosauten amathian, 386), e até mesmo narrativas correntes de antigas atrocidades humanas que envolveram, por ignorância, os próprios deuses. Tal como o boieiro bárbaro, Ifigénia contrapõe uma leitura racionalizada do mito, a partir de um pressuposto:

12 E. R. Dodds, The Greeks and the Irrational (Berkeley, Los Angeles 1973") 67-68: "In the Classical Age, intellectuals might limit the range of "divine madness" to certain types. A few, like the author of the late-fifth-century treatise de morbo sacro, might even go to the length of denying that any sickness is more "divine" than any other, holding that every disease is "divine" as being part of the divine order, but every disease as also natural causes which human reason can discover ...But it is unlikely that popular belief was much affected by all this, at any rate outside a few great cultural centres".

13 Esta nota racionalista, de crítica à facilidade popular de promover ao estatuto de manifestação divina tudo o que não é compreendido pela razão, parece ecoar a voz do poeta. 
um deus não pode ser kakos (386-391) ${ }^{14}$. Será esta uma última esperança posta na expetativa de sentido para a vida humana?...

O Coro de Jovens Servas Gregas, entre o final do episódio I e o início do episódio II, canta, de acordo com os parâmetros da tradição grega, os malefícios de uma esperança (elpis, 414) que impele os homens a traçar os seus caminhos por espaços cada vez mais vastos, mais alheados da própria identidade grega, em busca de riqueza. Esta é uma perspetiva própria de um mundo em vésperas de globalização - perspetiva que o próprio Horácio há-de formular mais tarde, em Horácio, nas suas Odes (1.1.13 sqq.). A viagem e a intervenção divina, aparentemente desconexa, juntou os dois irmãos. Ifigénia teve tempo, após os momentos de fragilidade visíveis no episódio I, de aprender a lição de dureza da sua existência e da sua sorte, aplicável, também, à das suas vítimas. Dessa sorte será ela o instrumento (466-481).

Faz, então, sentido que Orestes, interpelado por Ifigénia para que se identifique, o faça como o Ulisses de Odisseia perante o Ciclope - não como 'Ninguém', com o fim de enganar, mas como o 'Infortunado' (Dystyches, 500), ícone de todo o ser humano, impelido para um incessante e absurdo caminho por forças estranhas que determinam o rumo da sua vida e do seu fim.

Não fora este interrogatório, a que Orestes se esquiva de responder diretamente, pois pesa-lhe a sua própria identidade, e os topónimos de Argos e de Micenas não teriam sido mencionados como origem dos dois amigos (não irmãos). A breve disposição de Ifigénia de submeter à sua sorte de executora de sacrifícios é vencida pelo apelo da terra natal, da sua casa, da Hélade e do interesse em saber da sorte dos responsáveis pelo seu exílio e da sua família. Quando Orestes se queixa da volatilidade das palavras divinas, equivalentes à linguagem volátil dos sonhos, num contexto de confusão e sem-sentido da vida humana, é então que a ação se encaminha para o reconhecimento das personagens. Ele não é espontâneo, nem voluntário, mas nascido da fortuna, associada à natural reação das personagens no contexto situacional em que se encontram. O plano de Ifigénia de salvar um dos Gregos ligados a Micenas para ser portador de uma carta a seu irmão desencadeia uma contenda entre os amigos, verdadeira exibição de generosa philia, pois cada um deles quer ser

14 Vide Cropp comm. ad vv. 386-388. 
sacrificado e dar lugar à salvação do outro. Vencem os argumentos de Orestes e será Pílades o portador da carta. Daqui resulta, dramaticamente, que o discurso da missiva transmitida a Pílades se dirija ao seu companheiro ali presente, prestes a ser sacrificado, e a quem Ifigénia, sem o saber, suplica salvação. Pelo acaso que leva à escrita da carta Orestes fica a conhecer a identidade daquela que o deverá sacrificar - Ifigénia, que ele julgava morta.

Este reconhecimento tem sido sobejamente estudado e comentado desde o próprio Aristóteles, que várias vezes o aponta como modelar, na sua construção em duas fases ${ }^{15}$. Reconhece o filósofo que a mais perfeita anagnorisis é a que decorre dos próprios factos e dá como exemplo Rei Édipo e a carta de Ifigénia entre os Tauros (55a17-21).

O mesmo Aristóteles, ao falar do segundo momento do reconhecimento, o de Orestes a Ifigénia (1454b30-35), critica-o como «fabricado pelo poeta, por motivos que não têm que ver com a arte». Ele refere-se ao facto de Orestes se dar a conhecer espontaneamente, sem recorrer a sinais que, certamente, traria consigo (v. 795).

Em primeiro lugar, ficamos a perceber, por Aristóteles, que esta arquitetura do reconhecimento é original, concebida por Eurípides para esta peça. Em segundo lugar, há que ter em conta a preocupação de Aristóteles de sistematizar reconhecimentos associados a sinais ou aspetos materiais. A reação de Orestes decorre do júbilo e surpresa da carta cujo conteúdo ouve. Frente àquela que julgara morta, a sua explosão emocional não é mediada por sinais. Será mediada pelo conhecimento de factos, sugerindo a Ifigénia que o ponha à prova, inquirindo-o (809). Que outros sinais seriam mais expressivos que os testemunhos (tekmeria, 822) das recordações, partilhadas por dois seres humanos afastados do seu mundo e despojados de tudo o que lhes era familiar? Nesta tragédia da suprema errância o júbilo do reencontro desperta, ainda mais vivas, as memórias da pátria e a nostalgia de um regresso tido como impossível. Tentar esse regresso ou morrer juntos - eis a desesperada proposta de Orestes (1007 sqq.).

Ifigénia torna-se, então, talvez preparando a sua verdadeira assimilação a Ártemis, no culto em solo grego ${ }^{16}$, como a instância feminina que impele à vida

\footnotetext{
15 Poética $1452 \mathrm{~b} 6 ; 1454 \mathrm{a} 7 ; 1455 \mathrm{a} 20$.
}

16 Esta questão foi adequadamente investigada por A. M. Rebelo e constitui o cerne da sua dissertação de Mestrado Mito e Culto de Ifigénia Táurica, Coimbra, FLUC, 1993. 
e vincula à vida, ainda que instituída como sacerdotisa do sacrifício - que já não fará. A sua decisão de salvar Orestes suscitará a reação de esperança de Orestes, baseado numa espécie de enleio de leitura dos desígnios de Apolo e de Ártemis, a partir do oráculo várias vezes posto em causa. Talvez os deuses, se a tyche for propícia e os mortais aproveitarem o kairos, talvez assim eles ajudem ${ }^{17}$. No momento, é como mulher que Ifigénia pede a conivência das mulheres do Coro, mulheres gregas que, como ela, se associam a cantos bárbaros, com o seu coração marcado pela nostalgia da pátria perdida (1056-1064):

\section{IFIGÉNIA}

Ó mulheres, que me sois tão caras, é para vós que eu dirijo os meus olhos. O meu futuro está nas vossas mãos: ou me é dado ter êxito ou ser reduzida a nada e ficar privada da minha pátria, do meu irmão que tanto amo, de minha irmã tão querida.

Seja este o argumento em que me vou basear: somos todas mulheres, uma raça que nutre a afeição mútua, que busca preservar o bem comum. Mantende-vos, pois, em silêncio e ajudai-nos na fuga...

Essa conivência é a do silêncio, no plano do engano que o grupo dos três amigos/familiares irá pôr em prática, liderado por Ifigénia, para tentarem fugir no navio grego, rumo à Hélade. O rei bárbaro, na sua rusticidade ingénua de chefe de uma comunidade de pastores, enganado pelos jovens, antecipa, por um lado, o pai de Medeia na Cólquida; por outro lado, inscreve-se no padrão tipicamente euripidiano do Bárbaro de transparentes intentos e compromissos, frente ao Grego, mais refinado, mas doloso e pronto a quebrar compromissos, como atrás se referiu.

O plano quase executado contará com a força contrária do mar, que atira para a praia o grupo de fugitivos. O motivo romanesco do naufrágio associa, mais uma vez, a tyche e a obscura presença divina.

Será Atena quem, finalmente, surgindo ex machina, integrará os rasgos aparentemente desconexos das vontades divinas e da ação humana, chegada

17 Conacher, op. cit. 309, sublinha a forte interdependência entre tyche e kairos nesta tragédia, bem como a expressão de um profundo sentimento de saudade e de desejo de regresso ao lar das origens (p. 307). Veja-se também A. M. Rebelo, "O deus ex machina e o conceito de tyche na Ifigénia entre os Tauros, à luz da teoria aristotélica" Humanitas 47, t.1 (1995) 180 sqq. 
a uma aporia, e os articulará, conferindo-lhes sentido. A ação é conduzida aos parâmetros da tradição e associada à fundação de cultos iniciáticos em terras da Hélade, na Ática. Mas, mais ainda, na circularidade desta viagem, finalmente a ponto de ser bem sucedida, barbárie e helenidade articulam-se, num mundo onde já não é possível não interagirem.

Esta tragédia, pelos elementos romanescos que nela se deixam entrever, prenuncia a génese de novos géneros e de novos caminhos para a própria comédia.

Nota Withman ${ }^{18}$ : "Athena's prescription for the ceremonies of Halae prefigures, in part, the intellectual antiquarism of the Hellenistic age whose climax was Calimachus".

De facto, se tivermos em conta grande parte dos elementos peculiares do que até nós chegou da novela grega antiga ${ }^{19}$, verificamos que já estão presentes em Ifigénia entre os Tauros, tal como o motivo da separação do par amoroso, jovem e de classe privilegiada - neste caso trata-se de amor fraterno -, que, após muitas vicissitudes, se reencontra.

Tal reencontro pressupõe um espaço de antecedentes da ação dramática assaz vasto e ocorre num espaço estranho, fora da Hélade, preferencialmente Ásia Menor ou Próximo Oriente, mas, tal como na novela, as referências que a ele são feitas e as personagens que o habitam são inspiradas na realidade socioeconómica local: as regiões costeiras para além do Ponto Euxino eram, na Antiguidade Clássica, habitadas por comunidades que se dedicavam à agricultura e pastorícia.

Oráculos nebulosos, como nos Ephesiaka de Xenofonte, ou sonhos, ominosos mas nem sempre bem interpretados à partida, sublinham essa quebra de referências própria da errância por grandes espaços ou da crescente consciência do império da Tyche - a ponto de o desespero gerar a predisposição para o suicídio, ainda que não consumado.

O naufrágio que quase pôs fim aos planos de regresso à pátria dos jovens perdidos entre os Tauros constitui outro dos elementos caraterísticos da novela, num mundo onde a navegação, com rumos cada vez mais latos, conhece riscos, também cada vez mais frequentes. Por fim o regresso à pátria do par reunido é viável e consuma-se: no caso de Ifigénia, Orestes e Pílades, ainda sob a égide de

18 C. Whithman, Euripides and the Full Circle of Myth (Cambridge, Massachusetts 1974) 33.

19 Veja-se a excelente apresentação de elementos caraterísticos à novela antiga em N. Holzberg, Das antike Roman. Eine Einführung (Zürich 2001) 11-40. 
uma Atena unificadora e dadora de sentido a uma ação que tocou a aporia. Ela concatena passado mítico (laborado pelo poeta) e etiologia de cultos existentes, Apolo e Ártemis, nas suas manifestações nebulosas e desígnios incompatíveis, barbárie e helenidade (sob o signo do helenocentrismo). Reconhece, todavia, que, ainda que distantes e contestados, os deuses estão mais próximos dos homens, submetidos à mesma força que os rege: "O que tem de ser (to khreon, 1486)».

O Coro de Jovens Servas Gregas é também resgatado para regressar à Hélade, cujas recordações nostálgicas deram voz a pungentes cantos de saudade e recordações. Finalmente, tal como aos seus senhores, pode proclamar sua eutychia pelo regresso, visto e vivido como salvação (1490-1491) - a do homem restituído às suas raízes, depois de ter andado perdido em espaço estranho. Após o tempo de errância, desencontro, estranhamento e risco a acção das personagens desemboca no regresso possível à pátria, no encontro, na segurança do próprio reconhecimento do sentido que as peças dispersas do puzzle da existência passam a fazer, uma vez encaixadas, pelo esforço humano, pela Sorte e pela acção de instâncias superiores, nesta tragédia finessecular de happy end, eco de tempos em mudança, de uma nova época que se anuncia e em que a novela conhecerá o seu desabrochar.

Pouco a pouco, a fruição do mythos transferir-se-á da prevalência do espetáculo teatral para o livro, por parte já não da comunidade de cidadãos do universo da pólis, mas do kosmopolites, num universo expandido, de horizontes subitamente rasgados, em que a dimensão do individual e do contingente, a dependência da Sorte e a nostalgia do reencontro se fazem sentir e determinam um novo modo de cristalizar narrativamente a mimesis biou. 